\title{
O PODER HUMANIZADOR DA LITERATURA E A PERFORMANCE POÉTICA NA FORMAÇÃO DO LEITOR LITERÁRIO: UMA ABORDAGEM METODOLÓGICA
}

\author{
THE HUMANIZING POWER OF LITERATURE AND \\ POETIC PERFORMANCE IN THE FORMATION OF THE \\ LITERARY READER: A METHODOLOGICAL APPROACH
}

\author{
Margareth Torres de Alencar Costa* \\ Lucas Evangelista Saraiva Araújo*** \\ Elias Barroso da Silva Junior ${ }^{* * * * *}$
}

Resumo: O objetivo deste artigo é apresentar uma abordagem metodológica de ensino em literatura ao professor do ensino médio. Para tanto, foi utilizado como aporte teórico Nussbaum (1995, 2010); Carvalho (2017), Aguiar e Bordini (1993); Dalvi, Rezende e Faleiros (2013); Rouxel (2013); Paulino e Cosson (2009), dentre outros, para falar sobre o processo de humanização por parte da literatura, a importância de uma metodologia de ensino em literatura e a formação literária. Dessa maneira, propomos trabalhar com a leitura do poema e em seguida propor aos alunos a performance poética, a partir de Zumthor (2018). Nossa metodologia de pesquisa contou com uma pesquisa bibliográfica acerca das temáticas. Os resultados reafirmam que o poder humanizador da literatura e a performance poética, enquanto metodologias de ensino em literatura, podem ajudar o professor na formação de leitores em contexto escolar.

Palavras-chave: Literatura humanizadora; Performance poética; Formação de leitores.

Aвstract: The aim of this article is to present a methodological approach of teaching literature to high school teachers. With that end, Nussbaum $(1995,2010)$, Carvalho (2017), Aguiar and Bordini (1993), Dalvi, Rezende and Faleiros (2013), Rouxel (2013), Paulino and Cosson (2009), among others, were used as a theoretical contribution

\footnotetext{
"Doutora em Letras (Teoria Literária) pela Universidade Federal de Pernambuco e professora da graduação e do Programa de Pós-Graduação em Letras (PPGEL) da Universidade Estadual do Piauí (UESPI) e da Universidade Federal do Piauí (UFPI). E-mail: margarethtorres@cchl.uespi.br.

${ }^{* * *}$ Mestrando do Programa de Pós-Graduação em Letras (Estudos Literários) da Universidade Federal do Piauí. Licenciado em Letras Português e Inglês pelo Instituto de Ensino Superior Múltiplo (IESM). E-mail: lucasevansaraiva@gmail. com.

*** Mestrando do Programa de Pós-Graduação em Letras (Estudos Literários) da Universidade Federal do Piauí. Licenciado em Letras Português e Francês pela mesma instituição. E-mail: eliasbarroso@ufpi.edu.br.
} 
to talk about the process of humanization on the part of literature, the importance of a teaching methodology in literature and the formation literacy. Thus, we set to work with poem reading and then poetic performances with students, according to Zumthor (2018). Our methodology includes bibliographic research about the themes. The results reaffirm that the humanizing power of literature and poetic performance, as a teaching methodology in literature, can help teachers in the training of readers in educational contexts.

KEYwoRDs: Humanizing literature; Poetic performance; Reader formation.

\section{INTRODUÇÃO}

Passados trinta e sete anos da pesquisa feita em 1993, por Aguiar e Bordini (1993), acerca dos problemas do ensino de literatura no nível fundamental e médio no Rio Grande do Sul, ainda persistem metodologias de ensino de literatura que desprivilegiam o leitor-aluno na formação de leitores. Essa pesquisa foi de suma importância para os estudos feitos nessa época, pois mesmo sendo uma pesquisa feita no Rio Grande do Sul, serviu como parâmetro para uma compreensão sobre a realidade das escolas em todo o país. Muito embora sejam realidades distintas, o que faz jus a esse parâmetro é justamente o papel de todas as escolas brasileiras na formação/educação literária; aspecto presente na última versão da Base Nacional Comum Curricular (BNCC). As autoras discutem alternativas metodológicas no contexto dessa formação para que essas realidades não sejam diferentes, mas comuns.

O objetivo das autoras era elencar os problemas inerentes ao ensino de literatura, aos métodos de abordagem do texto literário em ambiente escolar, às metodologias utilizadas pelo professor, bem como a recepção dos textos literários pelos alunos da pesquisa. Nosso objetivo parte da defasagem encontrada na pesquisa das autoras e pretende apresentar uma abordagem metodológica ao professor do ensino médio, abordagem essa que pode ajudá-lo a ensinar literatura em sala de aula. Acrescentamos, a esse papel do professor na formação leitora dos alunos, o poder humanizador da literatura, além do indispensável papel da escola nessa formação. Neste ponto, iremos abordar a literatura como forma de humanização do leitor, e objetivamente vamos falar desse leitor em formação.

Pontuaremos o direito à literatura com Antônio Cândido (2006), para mostrar que essa arte deve estar presente em nossa vida, pois nela encontramos caminhos para pensar sobre si e sobre o mundo. Nessa caminhada, teremos também como apoio Martha Nussbaum (1995, 2010), para apontar a literatura como um processo de extrema importância para as humanidades e no processo de empatia com o próximo, haja vista que nela encontramos experiências diversas de vida, inclusive a nossa.

Todos esses pontos, baseados nas premissas da Estética da Recepção de Hans Robert Jauss (1994), e na Teoria do Efeito Estético de Wolfgang Iser (1996), de modo que todo esse 
arcabouço de teorias seja aplicado na criação de metodologias que incentivem os alunos tanto ao deleite como em seu processo de humanização a partir da literatura. Teremos Marileusa Cecília Carvalho (2017), que nos fala sobre uma didática de fruição da literatura, expondo a importância de uma metodologia que coloque o aluno e sua subjetividade em espaços privilegiados por meio de leituras performáticas e debates em sala abordando a temática do texto literário, colocando o professor como um mediador nesse processo.

Nesse contexto, temos uma abordagem metodológica que almeja dinamizar o ensino de literatura em meio a atual situação de pandemia ${ }^{1}$ vivida no país, e propõe uma reflexão sobre o ensino de literatura que, mesmo debaixo de limitações ocasionadas por essa situação, não pode parar, pois o leitor-aluno em formação, ao passo que adquire as competências e habilidades leitoras, pode encontrar, na leitura de textos em literatura, a humanização tão necessária dentro e fora de sala de aula.

Pretende-se, dessa maneira, trabalhar com a leitura do poema e, em seguida, propor aos alunos a performance poética a partir do que diz Zumthor (2018), que seria nossa metodologia para um repensar do ensino de literatura. Temos a finalidade de progredir metodologicamente com a leitura literária do poema, fazendo com que o leitor-aluno em formação do ensino médio, tendo um esperado horizonte de expectativas mais apurado, possa perceber que a leitura e a performance poética podem humanizá-lo significantemente.

Nossa proposta está subsidiada pelo método recepcional proposto por Aguiar e Bordini (1993), método que é pressuposto da Estética da Recepção de Jauss, que coloca o leitor como eixo de todo o processo literário, e que o vê como precursor da produção da obra literária, algo que será discutido de forma mais acentuada no tópico a seguir. Nossa proposta também se volta ao professor como modelo no processo de formação do leitor-aluno, por isso é colocado por nós como o performancer poeta modelo.

Espera-se que a nossa proposta de abordagem textual possa trazer à tona essas competências e habilidades, ao mesmo tempo que possibilita ao leitor-aluno a chance de ser a personagem-protagonista do processo de formação da leitura literária. Iremos abordar o texto literário poema, não só por ser uma abordagem recorrente em pesquisas e trabalhos acadêmicos, e que funciona bem, mas também pelo fato de o poema conter uma estrutura consideravelmente menor, sendo nosso ponto de partida para uma abordagem textual com estruturas composicionais maiores.

A seguir, fazemos uma discussão acerca do poder humanizador da literatura e logo em seguida fazemos uma breve discussão sobre alternativas metodológicas em Aguiar e Bordini (1993), dentre outros, e inserimos a essa discussão, apresentando dessa forma, a performance poética como proposta metodológica para o ensino de literatura na formação de leitores literários autônomos em sala de aula, voltada à questão do letramento literário (PAULINO; COSSON, 2009); fora da sala de aula, para as pesquisas e estudos que abordam temas como o nosso.

${ }^{1} \mathrm{O}$ artigo intitulado A pandemia de COVID-19 no Brasil: crônica de uma crise sanitária descreve esse contexto. 


\section{O PODER HUMANIZADOR DA LITERATURA}

A literatura possui a capacidade de nos levar em outras experiências que talvez nunca tenhamos em nossa vida, pois faz o leitor viajar pelo mundo. Além disso, por conta de toda essa capacidade de novas vivências "virtuais", como perguntou (CÂNDIDO 2006, p. 28) na sua dualidade: "qual a influência exercida pelo meio social sobre a obra de arte? [...] qual a influência exercida pela obra de arte sobre o meio?”, ela penetra nesse universo de influências.

A literatura possui a capacidade de criar empatia, ponto crucial na formação das humanidades, visto que nossas vidas possuem diversos problemas sociais que nos atingem: racismo, machismo, xenofobia, fome, escravidão e preconceitos de diversas formas. Quando não se faz parte de certos grupos estigmatizados, fica mais difícil de compreender a situação pela qual o outro está no mundo. Para isso, se faz necessário colocarmos o leitor como um sujeito ativo nesse processo, utilizando o professor como mediador dessa dialética entre texto e aluno. Para que isso ocorra, utilizaremos a "Experiência Estética" proposta por Jauss (1994), como base principal para a interpretação do texto, ao reivindicar o ingresso da história na metodologia de análise do texto literário e que, sobretudo, coloca o leitor e toda a sua subjetividade como protagonista nesse processo de interpretação.

Esse processo, como afirma Costa (1979), surgiu das perguntas não respondidas da Metafísica e das teorias platônicas do belo, que, até então, eram fundamentais no estudo da Estética. Jauss pretende acabar com uma dominância da interpretação e com uma visão de um leitor ideal para poder criar uma abordagem literária na qual todo leitor possa ter suas próprias experiências de acordo com o seu horizonte de expectativa.

Não seguir pelo caminho dos meios de interpretação mais convencionais daqueles que encerram o contexto da obra sem dar importância ao que o leitor poderia dizer sobre ela, seja ele especializado ou não, é o ponto principal dessa metodologia: colocar o leitor em primeiro plano e fazer com que ele ponha a obra em questão - seja ela um poema ou uma narrativa literária - no seu contexto de vivências, e não impondo uma interpretação finalizada que encerra a obra por determinado crítico ou pesquisador. Iser (1996) afirma que a literatura possui múltiplas facetas, que vai da sua interpretação até ao efeito que essa obra pode causar no leitor de acordo com seu horizonte de expectativas. Lembrando o que ele fala sobre esse viés:

Se é correto que através dos textos algo nos acontece, e que aparentemente não podemos nos separar das ficções - independentemente do que pensamos delas, sugere a pergunta pela função da literatura para a "constituição humana" (ISER, 1996, p. 17).

Os meios aos quais citamos aqui são de suma importância para a permanência do ensino de literatura nas escolas, pois não são apenas um meio de se aprender uma boa escrita do português, mas uma maneira de elevar o aluno a discussões que talvez sem a literatura 
ele não tenha a oportunidade de ter ou experienciar. Marta Nussbaum (2010) nos alerta para uma queda na importância das humanidades no processo de formação do ser humano, uma vez que atualmente só conseguimos ver importância nas ciências e na tecnologia para o nosso progresso.

Esse pensamento decorre da formação tecnicista em que preza por um indivíduo que apenas pretende visar bens materiais para ser considerado sujeito no mundo, mas que esse pensamento apenas se dá por uma visão vaga de experiência de nossas vidas. Necessitamos de mais do que avanços tecnológicos, precisamos ser humanos em primeiro ponto, precisamos de empatia com o próximo, e só nas humanidades e nas artes teremos esse apoio, assim como afirma Nussbaum (2010):

Estas capacidades estão ligadas às artes e às humanidades. Não estamos nos referindo à capacidade de desenvolver o pensamento crítico; a capacidade de transcender lealdades como "cidadãos do mundo"; e, finalmente, a capacidade de imaginar compassivamente as dificuldades dos outros (NUSSBAUM, 2010, p. 26, tradução nossa). ${ }^{2}$

Não é que estamos tentando impor um pensamento utilitarista para o ensino de literatura, longe disso. Estamos tentando mostrar que, através de uma leitura "ingênua”, tenhamos um deleite literário que ocorra para o prazer e que envolva nossas capacidades intelectuais, apenas reservadas aos seres humanos, visto que "nossas experiências de mundo não se circunscrevem meramente aos aspectos materiais e objetivos de reprodução e sobrevivência como seres biologicamente marcados por necessidades primárias (alimentação, proteção, reprodução)" (OLIVEIRA, 2014, p. 127). Mas tenhamos em mente que essa atividade literária também pode possibilitar vivências que nos tiram da nossa zona de conforto e isso também deve ser levado como prática pelo professor na hora de ensinar literatura.

Assim, observamos que apenas as tecnologias não são necessárias para nossa formação como cidadãos do mundo. Como seres racionais que vivem em sociedade, temos responsabilidade para a construção desta. Precisamos criar meios de sensibilidade e compreenção de aspectos sociais que também necessitam de um conjunto de conhecimentos, tais como história, geografia, entre outros.

Podemos nos aprofundar um pouco no campo da História, visto que essa nos conta, por exemplo, sobre a escravidão, seu horrores, as formas de tráfico de pessoas vindas da África e, sobretudo, os seus impactos na construção de um pensamento racista. Do outro lado temos narrativas literárias que contam a história de personagens negras que estão incluídas nesses contextos históricos, nos quais a literatura vai criar uma gama de efeitos que vai fazer com que

\footnotetext{
${ }^{2}$ Estas capacidades se vinculan con las artes y con las humanidades. No referimos a la capacidad de desarrollar un pensamiento crítico; la capacidad de transcender las lealtades como "ciudadanos del mundo"; y, por último, la capacidad de imaginar con compasión las dificultades del prójimo (NUSSBAUM, 2010, p. 26).
} 
o leitor seja capaz de vivenciar na pele da personagem o quanto esse período de escravidão foi perverso - óbvio que não se compara à experiencia de quem vive o racismo nos dias de hoje ou de quem viveu na época da escravidão, mas pode dar uma dimensão e criar um processo de empatia quanto à pauta de luta da comunidade negra - e sobretudo desumana com povos subalternizados. Assim explica Martha Nussbaum, com bases aristotélicas do entendimento sobre os efeitos da arte:

Arte literária, ele disse "mais filosófica" do que história, porque a história simplesmente nos mostra "o que aconteceu", enquanto as obras de arte literária nos mostram "coisas que podem acontecer" na vida humana. Em outras palavras, a história simplesmente registra o que de fato ocorreu, quer represente ou não uma possibilidade geral para vidas humanas. A literatura se concentra no possível, convidando seus leitores a se perguntarem sobre os duendes. Aristóteles está correto (NUSSBAUM, 1995, p. 5, tradução nossa). ${ }^{3}$

Dessa forma, sabemos que por meio da história podemos ficar informados e até horrorizados com determinados fatos do passado que são de extrema importância para se pensar o futuro. Agora, vamos imaginar uma experiência de maneira virtual. Esses pontos históricos fazem com que o aluno consiga imaginar a dimensão do ocorrido por meio da experiência estética gerada pela arte, assim nos vemos em dois pólos que se distinguem, mas se completam, dependendo do assunto tratado na obra mediada pelo professor: o aluno que apenas vê aqui na literatura e o outro aluno que se reconhece na literatura. Com isso, criam-se os meios de produção de empatia por parte do aluno que apenas experienciou virtualmente, com o aluno que se viu representado em uma problemática de determinada obra ou poema.

Em todo caso, levando em conta o horizonte de expectativas o segundo aluno - se o professor propor uma atividade que ponha em discussão o tema tratado - poderá dizer bem mais do que o primeiro, e será então o momento do primeiro aluno ouvir e se surpreender como o fato de que aquilo que ele viu virtualmente entra nos caminhos da realidade, e que seu colega de classe tem muito a dizer. Assim pensa Carvalho (2017), que propõe um ensino de literatura baseado na fruição, afirmando que uma escola que preza por uma educação crítica não pode ignorar a importância da literatura e que ela é direito de todos: "Poesia, prosa, drama, qualquer que seja o gênero literário, todos tornam a vida mais leve e mais alegre de ser vivida. E, certamente, esse é um direito de todos" (CARVALHO, 2017, p. 45).

\footnotetext{
${ }^{3}$ Literary art, he said "more philosophical" than history, because history simply shows us "what happened," whereas works of literary art show us "things such as might happen" in a human life. In other words, history simply records what in fact occurred, whether or not it represents a general possibility for human lives. Literature focuses on the possible, inviting its readers to wonder about them elves. Aristotle is correct (NUSSBAUM, 1995, p. 5).
} 
Ainda nesse mesmo engajamento, Carvalho (2017) afirma que a literatura possui um caráter de liberdade, uma forma de propor que o leitor viaje por diferentes espaços e experimente diferentes formar de viver, gerando sensibilidade:

A literatura traz ao leitor uma sensação de liberdade. Os livros, como mundos que se abrem a viagens, movimentam naqueles que leem experiências estéticas sugeridas pelo escritor, com o propósito de os sensibilizar, de fazer com que reflitam sobre sua própria existência, chegando, assim, mais próximos da liberdade (CARVALHO, 2017, p. 45).

No entanto, para que a literatura seja utilizada mediante aquilo que já foi discutido anteriormente, se faz necessário que haja uma metodologia que trabalhe com os alunos de maneira ativa, e que o professor esteja preparado para lidar com a leitura a ser feita em sala de aula, seja ela romance ou poesia, pois ele será o mediador dessa atividade de leitura e levará aos alunos uma proposta de discussão. Essa metodologia, como vimos anteriormente, deve tentar ao máximo não fazer com que a literatura seja tratada como obrigação para os alunos, pois isso causa desânimo no momento da leitura, e é um dos principais problemas do ensino de literatura no Brasil. Assim somos alertados:

A leitura de literatura que se faz na escola acaba quase sempre ganhando ares de "tarefa de casa". No mais das vezes e orientada pelo professor de Língua Portuguesa, seguida de avaliações. Ou seja, o prazer que deveria decorrer da leitura de uma obra literária acaba sendo aniquilado pelos "adereços" complementares do seu ensino. A leitura é tomada como mais uma obrigação que a escola cobra dos alunos (CARVALHO, 2017, p. 64).

Dessa forma, podemos notar que precisamos de mais metodologias que façam com que os alunos sejam provocados pela leitura e tenham prazer no ato de ler, como pensava Iser (1996), criando uma relação dialética entre sujeito e objeto, com o objetivo de que determinado texto cause algum efeito, levando o texto ao contexto do aluno, assim como pensava Jauss (1994) em sua Estética da Recepção.

\section{BREVE DISCUSSÃO SOBRE METODOLOGIAS DE ENSINO EM LITERATURA}

Em seu livro intitulado Literatura - formação de leitores: alternativas metodológicas, Aguiar e Bordini (1993) fazem preposições acerca de metodologias de ensino de literatura com o intuito de formar leitores. Propõem a necessidade de tais metodologias a partir dos resultados alcançados em sua pesquisa, que mostram que: 
A situação crítica do ensino de literatura tem sido suficientemente apontada e discutida em pesquisas, seminários, cursos, encontros de professores e no debate público em geral. Nessas ocasiões, verifica-se que o ponto nevrálgico da questão reside nas deficiências de domínio da leitura (AGUIAR; BORDINI, 1993, p. 32).

Segundo as autoras, um dos pontos que levam a essa situação é o fato do professor não ter acesso às fontes de informação que embasam suas metodologias de ensino, e apontam que a formação desses professores nos cursos de Letras ou Magistério, apesar dos pesares, possibilitou uma bagagem de assuntos que deveriam subsidiar esse ensino de forma mais efetiva.

O que se percebe, na fala das autoras, é que essa formação contribui com o ensino de literatura desenvolvido pelo professor em sala de aula, mas não é suficiente, por isso mais tarde irão falar que o professor precisa formar seus alunos, se formando. Ou seja, o professor precisa passar, sempre, pela formação contínua para que suas metodologias de ensino contemplem as atualidades dos alunos, suas necessidades.

Aguiar e Bordini (1993) enfatizam que o ponto crucial para essas deficiências está na leitura literária que o professor detém, pois, enquanto mediador de conteúdo, ele precisa ser um exemplo de leitor e incentivador da leitura em literatura. Entretanto, o que se vê na perspectiva da leitura literária em sala de sala é o apagamento daquilo que aluno sabe e pensa, focado em ensinar conteúdos em detrimento da leitura e dos benefícios que ela traz. Leitura essa que deveria ser "descompromissada, livre e estimulante da imaginação e da criatividade ou do senso crítico [...] não é, portanto, enfatizada" (AGUIAR; BORDINI, 1993, p. 33).

Já no diálogo entre a obra literária e o leitor, o professor é e precisa ser o mediador desse processo estritamente dialógico. É um diálogo, e ambos, obra e leitor, precisam ter abordagens próprias e que, na promoção de formar o leitor, este seja contemplado e privilegiado e aquelas, reiteradas como fonte para o desenvolvimento do aluno-leitor em formação. Esse é um dos papéis do professor nessa formação e a escola tem o papel de assegurar isso.

Um estudo mais recente, que data de 2014, aborda a importância desse diálogo e suscita uma prática de ensino ativa, que vai de encontro ao modo expositivo de aula, que coloca os alunos em postura apassivadora na relação com a obra. "Essa relevância dada ao diálogo aponta para uma prática de ensino mais dialógica [...] que ainda impera no ensino de literatura no nível médio e na universidade" (ALVES, 2014, p. 9).

Com o avanço de pesquisas como a de Aguiar e Bordini (1993), que se debruçam na promoção de alternativas metodológicas para o ensino de literatura na formação de leitores, estudos como esse de Alves (2014) e outros, com o passar do tempo, e ao passo que surgiam demandas de ensino, conseguiram por meio dos seus estudos, reafirmar a necessidade dessa discussão acerca dessas alternativas metodológicas. 
A partir de Silva (1998), as autoras Dalvi, Rezende e Faleiros (2013) propõem dez teses que dão norte ao trabalho com o texto literário na sala de aula. Dentre essas encontramos a décima tese voltada ao ensino médio, a qual diz:

Nos últimos anos do ensino fundamental, sobretudo, no ensino médio, torna-se indispensável, porém, fornecer aos alunos termos e conceitos fundamentais das gramáticas, da linguística, da genologia, da retórica e da poética, da história, da crítica e da teoria literárias mostrando, a partir dos textos e com os textos, sua utilidade e contribuição no processo de leitura - sem isso, são desnecessários (DALVI; REZENDE; FALEIROS, 2013, p. 81).

Para a autora, além de ser imprescindível o fornecimento desses conceitos aos alunos, é importante que a análise e a interpretação desses textos literários sejam realizadas com parcimônia, de forma clara e rigorosa. Todas essas especificações dizem respeito à terminologia das metalinguagens, que são utilizadas na descrição da própria linguagem tanto linguísticos como literários. A abordagem dessa terminologia não pode ser exacerbada, pois suas implicações na relação aluno-texto podem ser desastrosas.

Nesse contexto, Dalvi, Rezende e Faleiros (2013, p. 88) consideram alguns pontos importantes na avaliação do trabalho da literatura em sala de aula, por exemplo,

no caso específico do ensino [...] falar sobre os textos - esquadrinhando-os na multiplicidade de suas facetas - pode permitir instigar a manifestação dos conteúdos latentes e a aproximação de imagens e conteúdos aparentemente desarticulados.

Além disso, para a teórica, "não faz sentido, por exemplo, uma questão do ensino médio que peça que a estudante identifique [...] a métrica do poema ou coisa que o valha - a menos que tal informação esteja articulada a outras que maximizem a potência textual" (DALVI; REZENDE; FALEIROS, 2013, p. 89).

Esse falar é um bom caminho para se chegar a um entendimento desprovido de ingenuidade do fato literário. Ao passo que o aluno avança em sua escolaridade e idade, é preciso que as perguntas também acompanhem esse avanço, fazendo com que essas perguntas sejam mais elaboradas, direcionadas e interventivas. O desejo do aluno de intervir sobre determinada leitura deve ser estimulado e estipulado, e isso tem que reverberar principalmente no ensino médio.

Para Rouxel (2013),

no ensino médio [...] deve-se estimular a curiosidade por esses objetos estranhos cujos códigos linguísticos, éticos e estéticos são desconhecidos ou pouco conhecidos. A inventividade do professor é requisitada 
para elaborar um dispositivo capaz de interpelar os alunos (ROUXEL, 2013, p. 27).

Segundo a autora, para que seja uma recíproca alteridade entre o leitor e a obra, é preciso que os alunos leiam obras em sua totalidade e não unicamente fragmentos, pois a leitura literária a partir somente destes pode ser frustrante. Assim, a leitura integral "é a única capaz de modificar a relação dos alunos de ensino médio com o texto. A prática cursiva, que se pode discutir na sala, oferece possibilidades de renovação do ensino em literatura" (ROUXEL, 2013, p. 28), algo parecido com a prática de conversa literária como situação de ensino, corroborada por Bajour (2012).

Ainda em Alves (2014), encontramos um dos problemas para que esse diálogo não aconteça, ou que aconteça de forma insatisfatória. De acordo com o autor:

Um dos grandes problemas de formação do leitor passa a ser o ensino médio, momento no qual os conteúdos permanecem presos ainda a um historicismo um tanto mecânico e que não favorece o diálogo do leitor com os textos (ALVES, 2014, p. 10).

O que propomos aqui é uma metodologia que englobe o papel do professor enquanto exemplo de leitor das leituras que propõe aos seus alunos em sala de aula. Em estudos mais recentes, vemos que o planejamento das aulas de leitura em literatura precisa privilegiar esse aluno-leitor e não pode ser um momento apenas de leitura, um compromisso árduo e exigente, mas que seja o momento de ler e experienciar o texto literário, de discuti-lo.

Segundo Araújo (2019), encontramos esse planejamento como forma de estruturação de uma metodologia de ensino:

Em se tratando das aulas de leitura de literatura, muitas vezes os professores não compreendem a necessidade do planejamento. É preciso entender que a leitura de literatura comunica, provocando o leitor a interagir com o texto de maneira receptiva e simbólica (AMARILHA, 2010). Uma das características do texto literário é proporcionar prazer e conhecimento, como também uma experiência social, simbólica e educativa; por isso, o professor necessita planejar as aulas de leitura de literatura assim como as outras atividades e conteúdo que são organizados pelo professor (ARAÚJO, 2019, p. 740).

Esse planejamento deve ater-se não só ao suporte presente na escola ou na biblioteca, que é o livro didático. O professor precisa inserir, em sua metodologia de ensino, leituras de obras literárias propriamente ditas, ou começar a inserir, por ordem de séries, textos literários que abarquem o horizonte de expectativas do aluno. No entanto, encontramos geralmente o texto literário, ainda que de forma fragmentada, somente no livro didático, em que é pretexto para o ensino de gramática. 
Segundo Silva e Pontes (2019), é perceptível que

no contexto atual, a Literatura continua não sendo uma prioridade na sala de aula, tendo em vista estar associada ao ensino de Língua Portuguesa e, mais especificamente, se apresentar ao estudante por meio do livro didático (SILVA; PONTES, 2019, p. 1014).

Metodologicamente falando, a obra e/ou o texto literário precisam de um enfoque maior, sendo cabível abordar o texto literário, no livro didático, separado dos assuntos gramaticais. Cabe ao professor a responsabilidade de selecionar os textos adequados à realidade do aluno, podendo inserir, na sala de aula, extratextos a partir dessa realidade, que o professor deve mapear em uma das etapas do método recepcional e que não precisam necessariamente estar no livro didático fornecido pela escola.

Essa escolha é justificada pelo fato da experiência de leitura e o senso crítico do professor anteceder qualquer proposta metodológica. "Quando se trata de literatura, a experiência de leitura e o senso crítico do professor não podem ser substituídos pelo aparato metodológico, por mais aperfeiçoado e atualizado que este seja" (AGUIAR; BORDINI, 1993, p. 28). Esta proposição das autoras corrobora com nossa proposta metodológica, que vê o professor como guia na abordagem textual e que media, do início ao fim, todo o processo das habilidades e competências do aluno-leitor em formação.

"Se um professor se compromete com uma prosposta inovadora de educação no âmbito do ensino de literatura, é válido investir na formação de leitores" (AGUIAR, BORDINI, 1993). Como professores, almejamos proporcionar aos nossos alunos uma vivência diária de leitura literária, na escola, dentro e/ou fora da sala de sala, tendo como intuito formá-los reflexiva e criticamente enquantos leitores literários. Por isso, a nossa proposta, a seguir, pretende redimensionar e se possivel inovar, como afirmam as autoras, o ensino de literatura com uma metodologia que, por meio do método recepcional, privilegia e dá voz e vez ao aluno-leitor em constante formação educativa, leitora e humana.

O que queremos propor vai ao encontro de uma prática de leitura que

priorize o contato com os textos literários não de forma fragmentada, mas em sua totalidade e, de preferência, em seu suporte original, o livro literário, seja ele na forma física ou virtual. E que também sejam levadas em consideração as preferências dos alunos para que se possa fomentar o desejo pela leitura. Esta, prioritariamente, desvinculada de atividades mecânicas, cansativas para apenas alcançar propósitos didáticos previstos num currículo fechado e estanque (SILVA; PONTES, 2019, p. 1017). 
Nossa proposta de metodologia pretende dar prioridade a esse contato, e prevê a leitura de 3 poemas distintos em temática, níveis de linguagem e conteúdo, de 3 poetas brasileiros. Usaremos o método recepcional proposto por Aguiar e Bordini (1993) para subsidiá-la e colocá-la em prática.

\section{A POESIA ROMPE O ASFALTO}

O método recepcional será utilizado para alcançar nosso objetivo de apresentar uma abordagem metodológica ao professor do ensino médio, abordagem essa que pode ajudá-lo a ensinar literatura em sala de aula. As etapas desse método são: determinação do horizonte de expectativas; atendimento do horizonte de expectativas; ruptura do horizonte de expectativas; questionamento do horizonte de expectativas e ampliação do horizonte de expectativas (AGUIAR; BORDINI, 1996).

Por mais que a obra literária e o leitor estabeleçam uma relação dialógica, a obra precisa fornecer a esse leitor valores novos e diferentes daqueles por ele adquiridos. A obra precisa atrair o aluno e desafiá-lo a interpretá-la. Isto é, uma prática de leitura baseada nos pressupostos da Estética da Recepção que coloca a obra como "difícil”, "uma vez que nela reside o poder de transformação de esquemas ideológicos possíveis de crítica [...] insiste na qualificação dos leitores pela interação ativa com os textos e a sociedade" (AGUIAR; BORDINI, 1993, p. 85).

Os objetivos e critérios de avaliação desse método visam a desenvolver leituras compreensivas e críticas; proporcionar que o leitor seja receptivo a novos textos e a leituras de outrem e questionar mediante o seu horizonte cultural, as leituras feitas. Baseados nesses critérios, proporcionamos ao leitor a leitura dos poemas abaixo:

\section{A Hora do Cansaço - Carlos Drummond de Andrade}

As coisas que amamos, as pessoas que amamos são eternas até certo ponto.

Duram o infinito variável no limite de nosso poder de respirar a eternidade.

Pensá-las é pensar que não acabam nunca, dar-lhes moldura de granito.

De outra matéria se tornam, absoluta, numa outra (maior) realidade. 
Começam a esmaecer quando nos cansamos, e todos nos cansamos, por um outro itinerário, de aspirar a resina do eterno.

Já não pretendemos que sejam imperecíveis.

Restituímos cada ser e coisa à condição precária, rebaixamos o amor ao estado de utilidade.

Do sonho eterno fica esse gosto acre na boca ou na mente, sei lá, talvez no ar.

\section{Subversiva - Ferreira Gullar}

A poesia

Quando chega

Não respeita nada.

Nem pai nem mãe.

Quando ela chega

De qualquer de seus abismos

Desconhece o Estado e a Sociedade Civil

Infringe o Código de Águas

Relincha

Como puta

Nova

Em frente ao Palácio da Alvorada.

E só depois

Reconsidera: beija

Nos olhos os que ganham mal

Embala no colo

Os que têm sede de felicidade

E de justiça.

E promete incendiar o país.

\section{Rute no Campo-Adélia Prado}

No quarto pequeno

onde o amor não pode nem gemer

admiro minhas lágrimas no espelho, sou humana, 
quero o carinho que à ovelha mais fraca se dispensa.

Não parecem ser meus meus pensamentos.

Alguns versos restam inaproveitáveis,

belos como relíquias de ouro velho quebrado,

esquecidas no campo à sorte de quem as

respigue.

A nudez apazigua porque o corpo é inocente, só quer comer, casar, só pensa em núpcias,

comida quente na mesa comprida

pois sente fome, fome, muita fome

Esses poemas são os textos declamáveis no momento da performance poética, como está descrito no tópico seguinte. A perspectiva de Müller (2016) nos leva a crer que esses poemas, com essa linguagem e composição, não seriam encontrados no livro didático do ensino fundamental, quiçá no ensino médio, pois é:

comum nos livros didáticos analisados, temos a adoção de textos de menor extensão. Miniconto, poesia e letra de música nem sempre são explorados como gênero, muitas vezes são pretexto ou provocação para contextualizar a temática na abertura do capítulo ou um extra nos exercícios de interpretação de textos de outra natureza (MÜLLER, 2016, p. 22).

Queremos nos distanciar dessa abordagem do poema no livro didático e romper o asfalto da indiferença dessa abordagem desse suporte de ensino. A proposta visa a distribuir os poemas impressos numa turma de $3^{\circ}$ ano, com a finalidade de progredir metodologicamente com a leitura literária dos poemas rumo a leitura extensiva de contos e romances, fazendo com que o leitor-aluno em formação do ensino médio, tendo um esperado horizonte de expectativas mais apurado, possa perceber que a leitura e a performance poética podem humanizá-lo significantemente. "O poema assim se "joga": em cena (é a performance) ou no interior de um corpo e de um espírito (a leitura)” ZUMTHOR (2018, p. 61).

Quanto a linguagem, talvez haja o estranhamento do aluno no momento da leitura, contudo, essa linguagem é que confere ao poema o rompimento do asfalto do distanciamento colocado entre o leitor e o texto literário, por este ter esse tipo de linguagem. $O$ poema possui uma poética, uma construção de liberdade na linguagem inerente em sua estrutura e composição. "Literatura é indisciplina, e não é porque ela não prevê o que vai acontecer dentro de você. A literatura pergunta, ela não lhe dá resposta, lhe pergunta, lhe cutuca, está na poética do Aristóteles" (YUNES, 2012, p. 43). 
O momento de ter contato com esse tipo de linguagem é ao longo de toda vida, desde a contação de histórias ao bebê, passando por todas as fases da escolarização, uma vez que o letramento literário é um processo contínuo (PAULINO; COSSON, 2009). Esse processo diz respeito à educação literária progressiva preconizada pela Base Nacional Comum Curricular (BNCC, 2017). Diante disso, é necessário que essa prática transcenda as preposições desses autores, bem como tal base.

Contudo, Yunes (2012) nos subsidia nessa questão ao dizer que a linguagem literária:

pode apresentar o que está ausente (na ausência da presença) e tem outros níveis de representações cada vez mais sofisticados. Nós somos capazes de atravessar o muro de concreto, de entrar no mundo do desejo, estabelecer referências para coisas que aparentemente nunca vimos, a não ser no imaginário (YUNES, 2012, p. 17).

É o que visamos proporcionar ao aluno no momento da leitura dos poemas: a fruição; o desleite; o irreverente; uma transformação. A leitura transforma o leitor à medida que dialoga com o texto literário na busca não de respostas, mas de possíveis possibilidades de identificação ou de mudanças da sua realidade e sociabilidade. A leitura de um poema, por exemplo, conecta o leitor ao mundo.

Yunes (2012) defende que:

A leitura tem este poder transformador, tem este poder transformador das histórias, a leitura como um todo é a condição para eu me apossar do mundo. É lendo que se oferta a cidadania, o desejo de ser dono da própria história, de ter uma inserção no mundo, na sociedade e tudo isto vem da qualidade de uma informação articulada. Já dizia o filósofo Wittgenstein muito importante do século passado: o tamanho do mundo é o tamanho da sua linguagem (YUNES, 2012, p. 43).

O leitor-aluno em formação, ao passo que adquire as competências e habilidades leitoras, pode encontrar, na leitura de textos em literatura, a humanização tão necessária dentro e fora de sala de aula. Essas competências e habilidades leitoras são importantes para sua formação, por isso priorizar a caminhada do aluno-leitor no contato com o texto literário pode garantir que a recepção e a leitura desse texto pelo aluno seja um campo fértil e próspero em sua formação.

\section{A performance pó́tica caseira}

Após a tomada de posse da leitura dos poemas por parte do aluno-leitor, propomos que ele aprenda, internalize a leitura e decore-a para ser declamada e gravada em casa. Segundo 
Zumthor (2018), a performance vai além de como ela pode ser recebida, sua recepção, e se convence que:

a ideia de performance deveria ser amplamente estendida; ela deveria englobar o conjunto de fatos que compreende, hoje em dia, a palavra recepção, mas relaciono-a ao momento decisivo em que todos os elementos cristalizam em uma e para uma percepção sensorial - um engajamento do corpo (ZUMTHOR, 2018, p. 18).

Uma declamação dinâmica, subjetiva, feita a partir da execução do método recepcional, que dá ênfase ao horizonte de expectativas do leitor. Uma declamação que coloque o corpo em movimento, as expressões em evidências e a entonação como força dos sentidos contidos nos poemas. Por ser uma declamação caseira, cremos que o aluno poderá ter a liberdade poética mais desinibida, possivelmente solta. Para Zumthor (2018), a leitura literária e a performance se relacionam por meio de "um certo número de realidades e de valores, assim revelados, aparecem identicamente envolvidos na prática da leitura literária. Daí o lugar central que dou à ideia de "performance"” (ZUMTHOR, 2018, p. 27-28).

O passo a passo da nossa abordagem metodológica a partir dos poemas é: primeiro, mapeamento da experiência e do horizonte de leitura dos alunos; segundo, consideração dessa experiência e desse horizonte na escolha dos poemas; terceiro, leitura e discussão dos poemas; quarto, organização e preparação para a declamação; quinto, a gravação da declamação; sexto, a culminância das declamações.

Nossa proposta está pautada na leitura individual dos alunos, cada um em sua casa. Sem troca de leituras, somente o intercâmbio entre as declamações. Os poemas a serem declamados serão escolhidos por sorteio, para que não só gosto do aluno seja considerado, mas também a improvisação. Obedecendo as etapas do método recepcional, na etapa de determinação do horizonte de expectativas, primeiro o professor precisa atentar-se para o comportamento do aluno-leitor em formação na sua busca por livros na biblioteca da escola e se pede indicações de leituras/livros aos colegas ou ao próprio professor, por exemplo. O professor pode determinar o que o aluno gosta de ler, quais livros de literatura possui, o que está lendo no momento e se gosta de ler poemas.

Na etapa de atendimento desse horizonte de expectativas determinado pelas observações feitas, o professor deve introduzir poemas com temas e realidades próprias dos alunos. Segundo Rouxel, "trata-se de ao mesmo tempo, partir da recepção do aluno, de convidá-lo à aventura interpretativa com seus riscos, reforçando suas competências pela aquisição de saberes e de técnicas" ROUXEL (2013, p. 20). A partir dessa etapa, o professor é o leitor exemplo, pois precisa se predispor a declamar poemas que já leu, colocando na declamação o corpo no jogo literário, a expressão do que está sendo declamado, a entonação e o sentido que atribui por meio da declamação. 
Para (ZUMTHOR, 2018 p. 67): "Ao ato de ler integra-se um desejo de restabelecer a unidade da performance, essa unidade perdida para nós, de restituir a plenitude por um exercício pessoal, a postura, o ritmo respiratório, pela imaginação". Na etapa de ruptura do horizonte de expectativas, o professor pode propor a leitura dos poemas A Hora do Cansaço, de Carlos Drummond de Andrade, Subversiva de Ferreira Gullar e Rute no Campo de Adélia Prado, com o intuito de romper a bagagem de leituras de possíveis poemas que o aluno tenha lido. A etapa de questionamentos desse horizonte contaria com um debate/roda de conversa acerca das leituras feitas. Questões como: Qual a sua experiência com a leitura de textos literários como o poema? Você conhece o autor/poeta de algum poema lido? A partir da sua leitura, em que momento histórico cada poema foi escrito ou eles foram escritos no século XXI? O que o poema causou em você? Você gostou dessa leitura? Pretende ler mais poemas como esses? Por quê? Interprete-os a partir da sua visão.

Essa leitura dos poemas pelos alunos e a mediação do processo no diálogo de ambos, ajudará o professor na última etapa, que é ampliação do horizonte de expectativas desses alunos. Essa ampliação pode ser desenvolvida do início ao fim no processo de performance poética caseira. Em meio à pandemia, a proposta seria a produção de vídeos caseiros com as performances poéticas dos alunos, incentivados e monitorados pelo professor. Este será o performer poeta modelo, então começará a declamação. Os possíveis jurados serão outros professores de LP ou Literatura da escola ou fora dela.

A proposta se justifica pelo democrático acesso, ainda mais recorrente atualmente, dos alunos às tecnologias, a aparelhos celulares e apps de edição. A proposta se justifica também pelo debate, a discussão e atividades que extrapolam o ambiente da sala de aula, pautados na diversificação da concepção de leitura literária (AGUIAR; BORDINI, 1993). O debate será feito após as apresentações, que serão realizadas por meio de vídeos feitos caseiramente com o propósito de aguçar os interesses literários e o prazer do texto por meio do uso de tecnologias: celular e app para edição simples e acessível. O professor poderá auxiliá-los na edição, inserindo, antes dela, uma oficina de edição de vídeo, um treinamento.

As melhores apresentações ganham prêmios: livros desejados pelos alunos ganhadores e um brinde (a pensar) para os demais alunos como reafirmação do potencial de cada um. A leitura despretensiosa, com propósito, mas sem a obrigatoriedade da forma; o conteúdo, o texto literário como protagonista e o leitor como eixo de todo o processo literário. A exibição dessas performances deve ser feita de forma remota. Se o professor precisar avaliar o aluno, deve fazer isso de forma a levar em consideração não a quantidade de performances poéticas posteriores possíveis, mas a qualidade dessas performances na promoção da leitura autônoma e transformadora que o poema suscita no leitor-aluno em formação. 


\section{CoNSIDERAÇõES FINAIS}

Visto que Cândido (2017) vê o direito à literatura como de suma importância na compreensão e estudo de fenômenos sociais, e ainda como papel fundamental na formação de uma consciência coletiva que procura compreender as mazelas que assolam nossa sociedade, por meio dessa habilidade de ficcionalizar nossas experiências de vida, tivemos por objetivo primário acrescentar a voz de outros autores para tratar da literatura como papel muito importante no apoio das humanidades.

Com base no que foi desenvolvido ao longo deste trabalho, foi denotado o papel humanizador da literatura, de acordo com Nussbaum $(1995,2010)$, que tem como objetivo apontar a importância da literatura para a democracia e as humanidades, bem como processo de empatia, pois só por meio do texto literário podemos adentrar em uma realidade que não experienciamos pelas nossas vivências pessoais.

Da importância do seu ensino, e das boas práticas metodológicas em uma leitura de fruição, como afirmou Carvalho (2017), para melhor aplicar esse potencial de humanização por meio da mediação do professor com seus alunos, faz com que o aluno seja protagonista nesse processo, como explica Jauss (1994) por meio da Estética da Recepção. Dessa forma, é possível priorizar o horizonte de expectativas e o efeito estético no ato da leitura (ISER, 1996), principalmente em uma leitura performática

Acerca de metodologias que priorizam o aluno enquanto leitor no processo de formação leitora, vimos, a partir da discussão feita sobre alternativas metodológicas desenvolvidas em sala de aula a nível de ensino médio, que essa prioridade contribui para esse processo de formação de leitores. Na discussão, embasada pelas autoras e autores da área, pode-se perceber que a adoção de um método, além de auxiliar o professor no ensino de literatura, subsidia a prática de leitura pautada no próprio aluno.

A prática de leitura por meio da preposição da performance poética contribui bastante com a metodologia de ensino do professor na formação de alunos leitores do ensino médio que, por meio do método recepcional, pode fomentar melhor sua metodologia e seu objetivo em sala de aula, como prescreve Aguiar e Bordini (1993). Esse método, sendo utilizado pelo mediador, que é o professor, privilegia o leitor-aluno e parte do seu horizonte de expectativas para promover a leitura literária e, consequentemente, incita o hábito e o gosto por essa leitura, possibilitando as competências e habilidades leitoras desse leitor em formação, um saldo positivo de leituras literárias.

Logo, almejamos que esta produção possa contribuir com futuros estudos que venham a pesquisar sobre abordagens metodológicas no ensino de literatura, como a apresentada performance poética - que reflitam sobre o poder humanizador da literatura e a formação literária do aluno do ensino médio enquanto leitor. 


\section{REFERÊNCIAS}

AGUIAR, Vera Teixeira de; BORDINI, Maria da Glória. Literatura - a formação do leitor: alternativas metodológicas. 2. ed. Porto Alegre: Mercado Aberto, 1993.

ALVES, José Hélder Pinheiro (Org.) Memórias da Borborema 4: discutindo a literatura e seu ensino. Campina Grande: Abralic, 2014.

ARAÚJO, Jadilana Tavares Gonçalo de. Literatura na escola: saberes e práticas sob a perspectiva do docente. In: AMARILHA, Marly; TAVARES, Diva Sueli Silva; FREITAS, Alessandra Cardozo (org.). Educação e leitura: formar leitores, formando-se. Natal: EDUFRN, 2019, p. 740-755.

BAJOUR, Cecília. Ouvir estrelas: o valor da escola nas práticas de leitura. São Paulo: Editora Pulo do Gato, 2012.

BRASIL. Base Nacional Comum Curricular (BNCC). Educação é a Base. Brasília, MEC/CONSED/ UNDIME, 2017.

CANDIDO, Antônio. Literatura e Sociedade (revista pelo autor). Rio de Janeiro: Ouro sobre Azul, v. 117, 2006.

CARVALHO, Marileusa Cecília. Em busca de uma didática de fruição da literatura: contribuições de Aidam Chambers. Professare, v. 6, n. 1, 2017.

DALVI, Maria Amélia; REZENDE, Neide Luiza de; FALEIROS, Rita Jover. Leitura de literatura na escola. São Paulo: Parábola, 2013.

ISER, Wolfgang. $O$ ato da leitura: uma teoria do efeito estético. trad. de Johannes Kretschmer. São Paulo: Editora 34, 1996. v. 1.

JAUSS, Hans Robert. A história da literatura como provocação à teoria literária. São Paulo: Ed. Ática, 1994.

MÜLLER, Fernanda. Ensino de literatura nos anos finais do ensino fundamental: reflexões e alternativas. In: NASCIMENTO, Luciana; ASSIS, Lúcia Maria de; OLIVEIRA, Aroldo Magno (org.). Linguagem e ensino do texto: teoria e prática. São Paulo: Blucher, 2016, p. 13-40.

NUSSBAUM, Martha Craven. Poetic Justice. The literary imagination and public life. Boston: Beacon Press, 1995.

NUSSBAUM, Martha Craven. Sin fines de lucro: Por qué la democracia necesita de las humanidades. Rodil (Argentina): Katz editores, 2010.

OLIVEIRA, Luizir de. Éticae Estética, problemas de fronteiras: o diálogo entre a filosofia e a literatura/ Ethics and Aesthetics, boundary problems: dialogue between philosophy and literature. PensandoRevista de Filosofia, v. 5, n. 9, p. 124-145, 2014. 
PAULINO, Graça; COSSON, Rildo. Letramento Literário: para viver a literatura dentro e fora da escola. In: ZILBERMAN, Regina; RÖSING, Tânia M. K. Escola e leitura: velha crise, novas alternativas. São Paulo: Global, 2009.

SILVA, Hilma Liana Soares Garcia da; PONTES, Verônica Maria de Araújo. Leitura literária no ensino médio, uma prática associada ao livro didático. In: AMARILHA, Marly; TAVARES, Diva Sueli Silva; FREITAS, Alessandra Cardozo (org..). Educação e leitura: formar leitores, formandose. Natal: EDUFRN, 2019, p. 1013-1020.

YUNES, Eliana. Linguagem, educação e cultura: leituras. 1. ed. Salvador: Secretaria de Cultura do Estado da Bahia, Fundação Pedro Calmon, 2012.

ZUMTHOR, Paul. Performance, recepção, leitura. Ubu Editora LTDA-ME, 2018.

Recebido para publicação em: 10 set. 2021. Aceito para publicação em: 19 nov. 2021. 